\title{
Adsorption Efficiency of Chemically Modified Chitosan towards Copper and Cobalt Ions from Industrial Waste Water
}

\author{
Ragaa El-Sheikh, H.H. Hefni", A.F. El-Farargy, M. Bekhit* \\ and N.A. Negm* \\ Chemistry Department, Faculty of Science, Zagazig University, \\ Zagazig and *Petrochemicals Department, Egyptian Petraleum \\ Research Institute, Cairo, Egypt.
}

N THIS study, chitosan was produced and characterized using
NMR, IR, DSC and TGA analyses. Its molecular weight was
determined using GPC analysis. The produced chitosan was
chemically modified by reaction with glycine and chloroacetic acid. Its
adsorption capacity for $\mathrm{Cu}(\mathrm{II})$ and $\mathrm{Co}(\mathrm{II})$ ions from industrial
wastewater was determined and compared to the virgin chitosan. The
chemical structures of the prepared biosorbents were confirmed by
FTIR and ${ }^{1} \mathrm{H}-\mathrm{NMR}$. The adsorption efficiencies of the two biosorbents
in neutral (pH=7) and alkaline medium (pH=9) at $25^{\circ} \mathrm{C}$ were
determined using atomic absorption spectroscopy (AAS) and thermo-
gravimetric analysis (TGA). The two biosorbents show lower
adsorption efficiency towards copper and cobalt ions compared to the
virgin biosorbent (pure chitosan). Furthermore, the adsorption capacity
of glycine-chitosan was higher than the chloroacetic acid-chitosan
biosorbents, which is attributed to the chelating effect of the amino
groups than the chloro-substituted polymer.

Keywords: Chitosan, Industrial waste water, Cobalt and Copper ions.

Today, the pollution problem is the contamination of waters by heavy metals ${ }^{(1)}$. Traditional treatment methods such as chemical precipitation as metal hydroxide, electro deposition, ion exchange, and membrane separation have been applied. Adsorption seems to be a good alternative, and many adsorbents have been tested for the adsorption of various heavy metals. Chitosan has undoubtedly been one of the most popular adsorbents for the removal of metal ions from aqueous solution and is widely used in waste treatment applications ${ }^{(2-5)}$. In spite of its prolific use, the adsorption ability of chitosan has not been realized to a satisfying level. In the recent years, attention has been focused on various adsorbents that have metalbinding capacities and high selectivity to remove unwanted heavy metals from contaminated water ${ }^{(6,7)}$. Further chemical modifications of chitosan have been made to improve the selectivity and the capacities for metal ions ${ }^{(8)}$. Substituted chitosan was prepared and regarded as a simple and effective process to facilitate the adsorption ability of chitosan with heavy metals ${ }^{(9-10)}$.

*Corresponding author: nabelnegm@ hotmail.com 


\section{Experimental}

Materials

$\mathrm{CuSO}_{4}, \mathrm{CoSO}_{4}, \mathrm{NH}_{4} \mathrm{OH}$, and chitosan were purchased from Chimia Misr Company and were used without purification. The transition metals solutions were prepared by dissolving $\mathrm{CuSO}_{4}$ and $\mathrm{CoSO}_{4}$ in deionized water. Chitosan was washed in deionized water several times and dried at $50^{\circ} \mathrm{C}$ for $12 \mathrm{hr}$.

\section{Preparation of chitosan derivatives}

Equivalent molar amount of the chitosan (relative to the aminoglucose unit) and glycine or chloroacetic acid was reacted in xylene as solvent at $130^{\circ} \mathrm{C}$ for $3 \mathrm{hr}$ to eliminate the water of the reaction by Dean-stark connection. The reaction was stopped when the equivalent amount of water was obtained. The products were distilled off and dried in vacuum oven at $80^{\circ} \mathrm{C}$ then washed by bidistilled water and then dried in vacuum oven at $50^{\circ} \mathrm{C}$. IR spectra were used to confirm the structure of the modified chitosan polymer (Fig. $1 \& 2$ ).

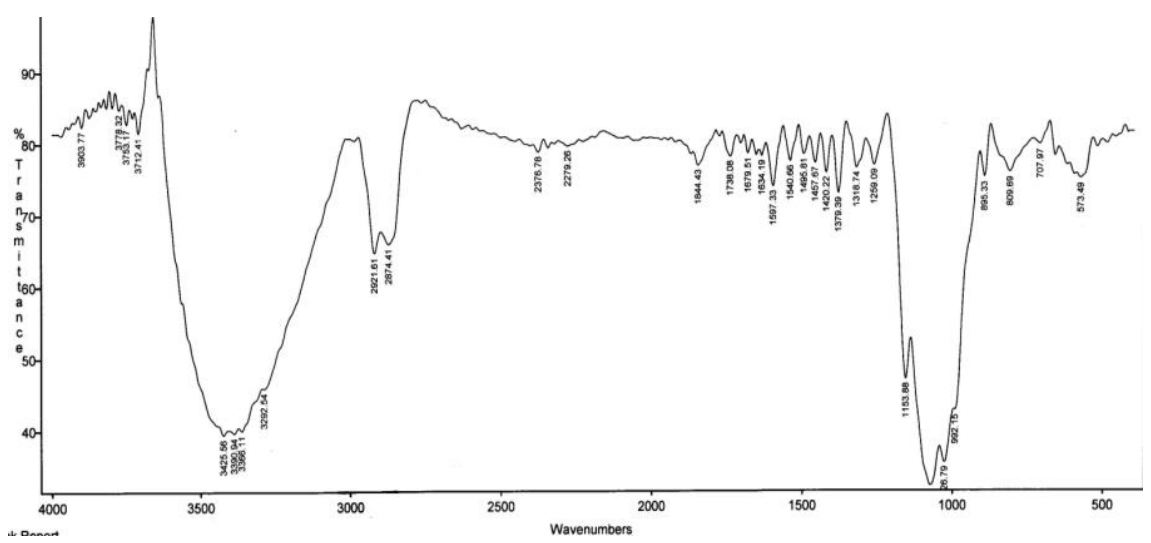

Fig. 1. IR spectra of chitosan biopolymer.

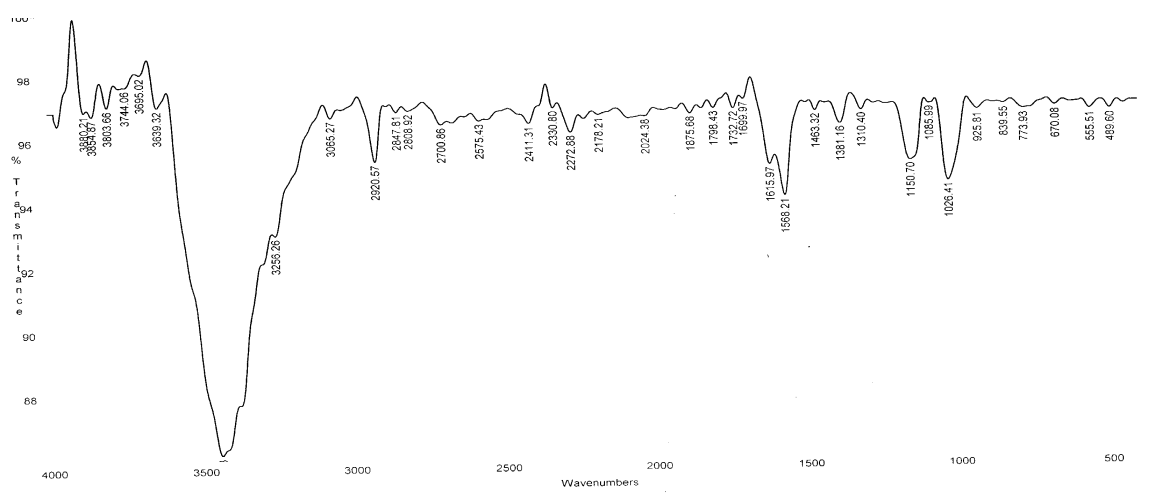

Fig. 2. IR spectra of chitosan-chloroacetic acid biopolymer.

Egypt. J. Chem. 55, No.3 (2012) 


\section{The adsorption studies}

The copper (II) and cobalt (II) solutions were prepared by diluting these metal ions from their stock solution $\left(1 \mathrm{gl}^{-1}\right)$, which was obtained by dissolving $\mathrm{CuSO}_{4} \cdot 2 \mathrm{H}_{2} \mathrm{O}, \mathrm{CoSO}_{4} \cdot \mathrm{H}_{2} \mathrm{O}$ in deionized water. For each treatment, $0.5 \mathrm{~g}$ of chitosan or its derivatives was added into $100 \mathrm{ml}$ of metal ion (II) solution (250 ppm) in $250 \mathrm{ml}$ Erlenmeyer flask. The flasks were agitated $(150 \mathrm{rpm})$ at $25{ }^{\circ} \mathrm{C}$ for different interval times 30, 60, 90, 120 and $150 \mathrm{~min}$. The polymers then were separated by vacuum filtration.

Several experiments were conducted to evaluate the effect of $\mathrm{pH}$ on biosorption at neutral and alkaline medium (7.0 and 9.0, at $250 \mathrm{ppm}$ solution of the different metals).

The residual metal concentrations remained in the solutions after the treatments by the biosorbents were determined using atomic absorption spectroscopy (AAS) and TGA analysis.

Data processing

The percent removal $(\eta \%)$ and the equilibrium adsorption capacity $\mathrm{q}_{\mathrm{e}}$ $\left(\mathrm{mg} \mathrm{g}^{-1}\right)$ of $\mathrm{M}(\mathrm{II})$ in the solution were calculated using Eq $(1,2)$, respectively.

$$
\begin{aligned}
\eta & =\frac{C_{0}-C_{e}}{C_{0}} \times 100 \% \\
q_{e} & =\left(C_{0}-C_{e}\right) \frac{V}{M}
\end{aligned}
$$

where $\eta(\%)$ is the percent removal, $\mathrm{q}_{\mathrm{e}}\left(\mathrm{mg} \mathrm{g}^{-1}\right)$ is the amount of adsorbed $\mathrm{M}(\mathrm{II})$ per unit mass at equilibrium, and $\mathrm{C}_{\mathrm{o}}\left(\mathrm{mg} \mathrm{L}^{-1}\right)$ is the initial concentration of the $\mathrm{M}$ (II) solution. $\mathrm{C}_{\mathrm{e}}\left(\mathrm{mg} \mathrm{L}^{-1}\right), \mathrm{M}(\mathrm{g})$ and $\mathrm{V}(\mathrm{L})$ are the equilibrium concentration of the $\mathrm{M}$ (II) solution, the mass of biosorbent and the volume of M(II) solution, respectively.

Table 1 lists the efficiencies and the equilibrium constants of the chitosan biopolymers and its modified forms.

The pseudo-first-order, pseudo-second-order kinetic models and the intraparticle diffusion model were used to study the adsorption kinetics of M(II).

The pseudo-second-order kinetic model has the general expression ${ }^{(1,2)}$ :

$$
\frac{t}{q_{t}}=\frac{1}{k_{2} q_{e}^{2}}+\frac{t}{q_{e}}
$$

where $\mathrm{q}_{\mathrm{t}}\left(\mathrm{mg} \mathrm{g}^{-1}\right)$ is the amount of $\mathrm{M}(\mathrm{II})$ adsorbed on the adsorbent at time $\mathrm{t}, \mathrm{k}_{2}$ $\left(\mathrm{g} \mathrm{mg}^{-1} \mathrm{~min}^{-1}\right)$ is the rate constants for the pseudo-second order kinetic models, respectively. 
The intraparticle diffusion model equation ${ }^{(11)}$ is:

$$
q_{t}=k_{\mathrm{i}} t^{1 / 2}+C
$$

where $\mathrm{k}_{\mathrm{i}}\left(\mathrm{mg} \mathrm{g}^{-1} \mathrm{~min}^{-1 / 2}\right)$ is the intraparticle diffusion rate constant and $\mathrm{C}(\mathrm{mg}$ $\mathrm{g}^{-1}$ ) is a constant related to thickness of adsorbed layer.

The Langmuir adsorption model is adopted most commonly to describe the adsorption behaviors of heavy metal ions in aqueous solution.

The Langmuir isotherm is represented in linear forms ${ }^{(12)}$ and mathematically represented using $\mathrm{Eq}$ (5).

$$
\frac{C_{e}}{q_{e}}=\frac{1}{k_{L} q_{\max }}+\frac{C_{e}}{q_{\max }}
$$

where $\mathrm{q}_{\max }\left(\mathrm{mg} \mathrm{g}^{-1}\right)$ is the maximum adsorption capacity at the equilibrium, and $\mathrm{k}_{\mathrm{L}}\left(\mathrm{L} \mathrm{mg}^{-1}\right)$ is the Langmuir constant.

\section{Results and Discussion}

\section{Adsorption capacity of the biosorbents}

Data in Table 1 represent the remaining amounts and adsorption capacities of the different biosorbents in presence of the different metal ions. The adsorption capacitances of the metal ions were in their highest values in presence of the unmodified chitosan in the alkaline medium. While, in the neutral medium, the adsorption tendency decreases considerably.

The maximum adsorption capacitance reached to $99 \%$ in case of unmodified chitosan in presence of both $\mathrm{Cu}$ (II) and $\mathrm{Co}$ (II) metal ions in the alkaline medium and $64 \%, 51 \%$ in the neutral medium. In case of compounds I \& II, the capacitance reached to $66 \%, 59 \%$ for $\mathrm{Cu}(\mathrm{II})$ and $54 \%, 38 \%$ in the neutral medium; and $62 \%, 64 \%$ for $\mathrm{Cu}(\mathrm{II})$ and $82 \%, 98 \%$ for $\mathrm{Co}(\mathrm{II})$ in alkaline medium. The data obtained from Table 1 showed the acceptable efficiency of the chitosan and its modified forms to remove $\mathrm{Cu}$ (II) and $\mathrm{Co}$ (II) metal ions from the wastewater after adjusting the $\mathrm{pH}$ of the medium to suitable values. 
TABLE 1. Percent removal ( $\eta \%$ ) and the equilibrium concentration $\left(\mathrm{C}_{\mathrm{e}}\right)$ of $\mathrm{Co}(\mathrm{II})$ and $\mathrm{Cu}(\mathrm{II})$ onto chitosan and its derivatives.

\begin{tabular}{|c|c|c|c|c|c|c|c|c|c|c|}
\hline \multirow{2}{*}{ Comp. } & \multirow{2}{*}{$t(\min )$} & \multirow{2}{*}{$\begin{array}{c}\mathrm{C}_{0} \\
\left(\mathrm{mg} \mathrm{L}^{-1}\right)\end{array}$} & \multicolumn{2}{|c|}{ Co (pH 7) } & \multicolumn{2}{|c|}{ Co (pH 9) } & \multicolumn{2}{|c|}{$\mathrm{Cu}(\mathrm{pH}$ 7) } & \multicolumn{2}{|c|}{$\mathrm{Cu}$ (pH 9) } \\
\hline & & & $\mathrm{C}_{\mathrm{e}},\left(\mathrm{mg} \mathrm{L}^{-1}\right)$ & $\eta \%$ & $\mathrm{C}_{\mathrm{e}},\left(\mathrm{mg} \mathrm{L}^{-1}\right)$ & $\eta \%$ & $\mathrm{C}_{\mathrm{e}},\left(\mathrm{mg} \mathrm{L}^{-1}\right)$ & $\eta \%$ & $\mathrm{C}_{\mathrm{e}},\left(\mathrm{mg} \mathrm{L}^{-1}\right)$ & $\eta \%$ \\
\hline Chitosan & $\begin{array}{c}20 \\
40 \\
60 \\
80 \\
100\end{array}$ & $\begin{array}{l}250 \\
250 \\
250 \\
250 \\
250\end{array}$ & $\begin{array}{l}123.6 \\
128.3 \\
129.5 \\
132.2 \\
132.2\end{array}$ & $\begin{array}{l}50.56 \\
48.68 \\
48.20 \\
47.14 \\
47.13\end{array}$ & $\begin{array}{l}0.27 \\
0.86 \\
1.52 \\
1.63 \\
1.63\end{array}$ & $\begin{array}{l}99.89 \\
99.65 \\
99.39 \\
99.35 \\
99.35\end{array}$ & $\begin{array}{l}90.8 \\
86.7 \\
77.8 \\
65.3 \\
65.3\end{array}$ & $\begin{array}{l}63.85 \\
65.32 \\
68.86 \\
73.88 \\
73.91\end{array}$ & $\begin{array}{c}2 \\
1.8 \\
0.7 \\
0.6 \\
0.8\end{array}$ & $\begin{array}{l}99.20 \\
99.33 \\
99.74 \\
99.75 \\
99.76\end{array}$ \\
\hline Comp.(I) & $\begin{array}{c}20 \\
40 \\
60 \\
80 \\
100\end{array}$ & $\begin{array}{l}250 \\
250 \\
250 \\
250 \\
250\end{array}$ & $\begin{array}{l}116.3 \\
171.3 \\
181.8 \\
182.5 \\
183.5\end{array}$ & $\begin{array}{l}53.48 \\
31.48 \\
27.28 \\
27.00 \\
26.60\end{array}$ & $\begin{array}{l}46.3 \\
50.4 \\
54.3 \\
54.5 \\
54.6\end{array}$ & $\begin{array}{l}81.48 \\
79.86 \\
78.26 \\
78.20 \\
78.15\end{array}$ & $\begin{array}{c}84.8 \\
89.5 \\
91.5 \\
102.1 \\
108.8\end{array}$ & $\begin{array}{l}66.07 \\
64.21 \\
63.39 \\
59.16 \\
56.48\end{array}$ & $\begin{array}{l}92.5 \\
92.7 \\
90.9 \\
87.3 \\
86.8\end{array}$ & $\begin{array}{l}62.99 \\
63.12 \\
63.62 \\
65.20 \\
65.28\end{array}$ \\
\hline $\begin{array}{c}\text { Comp. } \\
\text { (II) }\end{array}$ & $\begin{array}{c}20 \\
40 \\
60 \\
80 \\
100\end{array}$ & $\begin{array}{l}250 \\
250 \\
250 \\
250 \\
250\end{array}$ & $\begin{array}{l}154.4 \\
155.1 \\
157.6 \\
163.7 \\
163.9\end{array}$ & $\begin{array}{l}38.24 \\
37.96 \\
36.96 \\
34.52 \\
34.44\end{array}$ & $\begin{array}{c}4.3 \\
4.7 \\
5.8 \\
12.0 \\
12.2\end{array}$ & $\begin{array}{l}98.28 \\
98.21 \\
97.69 \\
95.20 \\
95.12\end{array}$ & $\begin{array}{c}102.5 \\
101.5 \\
90.2 \\
86.0 \\
85.4\end{array}$ & $\begin{array}{l}59.00 \\
59.40 \\
63.92 \\
65.61 \\
65.84\end{array}$ & $\begin{array}{l}88.0 \\
81.6 \\
51.6 \\
17.7 \\
14.9\end{array}$ & $\begin{array}{l}64.80 \\
67.42 \\
79.46 \\
92.90 \\
94.03\end{array}$ \\
\hline
\end{tabular}

\section{Effect of $\mathrm{pH}$}

The dominant species of $\mathrm{M}(\mathrm{II})$ ions are present in solution at different $\mathrm{pHs}$ in forms such as $\mathrm{M}^{2+}, \mathrm{M}(\mathrm{OH})_{2}, \mathrm{M}(\mathrm{OH})_{3}{ }^{-}$and $\mathrm{M}(\mathrm{OH})_{4}{ }^{2-}{ }^{(13)}$. At $\mathrm{pH}>7$, the precipitation of $\mathrm{M}(\mathrm{OH})_{2}$ plays the main role in removing $\mathrm{M}(\mathrm{II}){ }^{(14)}$. Adsorption of $\mathrm{M}$ (II) by chitosan or its derivatives as a function of $\mathrm{pH}$ is shown in Table 1.

In the neutral medium, the average adsorption capacity of $\mathrm{Co}(\mathrm{II})$ in the solution using the different adsorbents ranges between $51 \%$ and $38 \%$. These values are relatively low, which can be attributed to the ionic species of the metal ions in the solution. The neutral medium decreases the charges of the metal ions and the adsorbents which decrease their interaction by the adsorbents.

In the alkaline medium, the percentage of $\mathrm{M}$ (II) removal increased by increasing $\mathrm{pH}$ from 7.0 to 9.0. The low efficiency of the biosorbents at $\mathrm{pH} 7.0$ could be due to the increase in competition for adsorption sites by $\mathrm{H}^{+}$and $\mathrm{M}^{2+}{ }^{215-16)}$. As $\mathrm{pH}$ increased, more negatively charged surface sites became available thus facilitating greater M(II) adsorption. The results indicated in Table 1 revealed that there were excess hydroxide ions surrounding adsorbents surface resulting in the superior buffering effect of adsorbents and thereby revealed the possibility of $\mathrm{M}(\mathrm{II})$ precipitates on adsorbents surface ${ }^{(17)}$. 


\section{Effect of contact time}

Samples were taken at different time periods ranging from 20 to $100 \mathrm{~min}$ and the remaining concentrations of $\mathrm{M}$ (II) in the solutions were determined by AAS. In case of $\mathrm{Co}(\mathrm{II})$ ions at $\mathrm{pH} 7$ and 9. The saturation of adsorption on surfaces of all prepared compounds occurred at initial time $(20 \mathrm{~min})$, by increasing time, the Co(II) leaves the surfaces of adsorbents, due to the weak complexation and adsorption $^{(18)}$ between $\mathrm{Co}(\mathrm{II})$ ions and the main groups of adsorbents. While in case of $\mathrm{Cu}$ (II) ions, the adsorption increased by time increasing which corresponds to the coordination type (Fig. 3).

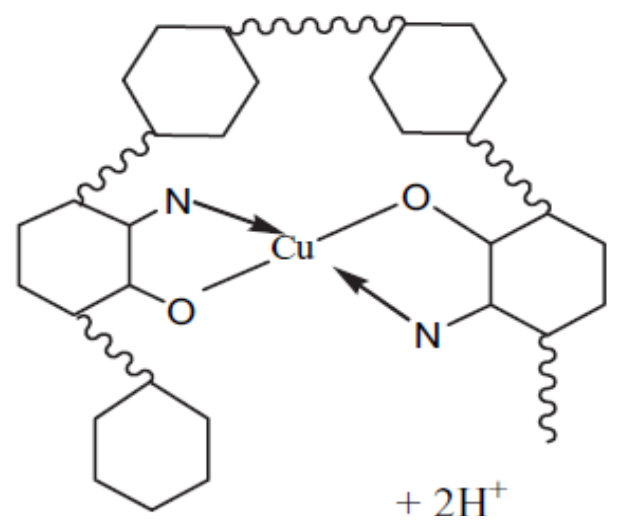

Fig. 3. The complex form between $\mathrm{Cu}(\mathrm{II})$ and the adsorbents molecule.

\section{Adsorption kinetics}

The kinetic parameters were studied using $250 \mathrm{ppm}$ of $\mathrm{M}(\mathrm{II})$ under the condition of $\mathrm{pH} \mathrm{7,9}$ and $0.5 \mathrm{gL}^{-1}$ adsorbent dosage, and $25^{\circ} \mathrm{C}$ temperature, and the concentration of $\mathrm{M}(\mathrm{II})$ remaining was analyzed at regular intervals during the process.

Several models describe the adsorption of the transition metal ions on the biosorbents. These models are including: pseudo-first-order kinetic, pseudosecond-order kinetic, first-order reversible reaction model and intraparticle diffusion model ${ }^{(19-21)}$.

The data were fit to pseudo-second-order kinetics and the intraparticle diffusion model as potential models for the behavior of $\mathrm{M}$ (II) adsorption. The adsorption kinetic parameters are given in Tables $2 \& 3$, respectively.

Egypt. J. Chem. 55, No.3 (2012) 
TABLE 2. Kinetic parameters for pseudo-second-order equation.

\begin{tabular}{|c|c|c|c|c|c|c|c|c|}
\hline \multirow[b]{2}{*}{ Comp. } & \multicolumn{2}{|c|}{ Co (pH 7) } & \multicolumn{2}{|c|}{ Co (pH 9) } & \multicolumn{2}{|c|}{$\mathrm{Cu}(\mathbf{p H} 7)$} & \multicolumn{2}{|c|}{ Cu (pH 9) } \\
\hline & $\left(\begin{array}{c}\mathbf{q}_{\mathbf{e}} \\
\left.\mathbf{m g ~ g}^{-1}\right)\end{array}\right.$ & $\left(\mathrm{g} \mathrm{mg}^{-1} \min ^{-1}\right)$ & $\underset{\left(\mathbf{m g ~ g}^{-1}\right)}{\mathbf{q u}^{-1}}$ & $\left(\mathrm{~g} \mathrm{mg}^{-1} \min ^{-1}\right)$ & $\underset{\left(\mathbf{m g ~ g}^{-1}\right)}{\mathbf{q u}^{-1}}$ & $\left(\mathrm{~g} \mathrm{mg}^{-1{ }^{-1}} \min ^{-1}\right)$ & $\underset{\left(\mathbf{m g ~ g}^{-1}\right)}{\mathbf{q u}^{-1}}$ & $\left(\mathrm{~g} \mathrm{mg}^{-1} \min ^{-1}\right)$ \\
\hline Chitosan & 115.4 & 0.0044 & 247.3 & 0.0247 & 196.08 & 0.0008 & 249.91 & 0.0220 \\
\hline Comp.(I) & 59.1 & 0.0017 & 193.1 & 0.0048 & 175.12 & 0.0010 & 165.48 & 0.0038 \\
\hline Comp.(II) & 82.9 & 0.0029 & 234.9 & 0.0030 & 165.91 & 0.0014 & 281.28 & 0.0002 \\
\hline
\end{tabular}

TABLE 3. Intraparticle diffusion model constants for the adsorption of Co(II) and $\mathrm{Cu}(\mathrm{II})$ onto chitosan and its derivatives.

\begin{tabular}{|c|c|c|c|c|c|c|c|c|}
\hline \multirow[b]{2}{*}{ Comp. } & \multicolumn{2}{|c|}{ Co (pH 7) } & \multicolumn{2}{|c|}{ Co (pH 9) } & \multicolumn{2}{|c|}{$\mathrm{Cu}(\mathrm{pH} 7)$} & \multicolumn{2}{|c|}{ Cu (pH 9) } \\
\hline & $\begin{array}{c}\mathrm{K}_{\mathrm{i}} \\
\left(\mathrm{mg} \mathrm{g}^{-1} \min ^{-1 / 2}\right)\end{array}$ & C & $\begin{array}{c}\mathrm{K}_{\mathrm{i}} \\
\left(\mathrm{mg} \mathrm{g}^{-1} \min ^{-1 / 2}\right)\end{array}$ & C & $\left(\begin{array}{c}\mathrm{K}_{\mathrm{i}} \\
\left(\mathrm{mg} \mathrm{g}^{-1} \min ^{-1 / 2}\right)\end{array}\right.$ & $\mathbf{C}$ & $\begin{array}{c}\mathrm{K}_{\mathrm{i}} \\
\left(\mathrm{mg} \mathrm{g}^{-1} \min ^{-1 / 2}\right)\end{array}$ & C \\
\hline Chitosan & 0.60 & 79.88 & 2.66 & 688.65 & 0.18 & 23.36 & 2.98 & 734.34 \\
\hline Comp.(I) & 0.07 & 12.89 & 0.56 & 117.71 & 0.20 & 23.61 & 0.70 & 104.79 \\
\hline Comp.(II) & 0.44 & 47.63 & 0.48 & 124.52 & 0.24 & 28.65 & 0.06 & 4.62 \\
\hline
\end{tabular}

The correlation coefficients $\left(\mathrm{R}^{2}\right)$ for the pseudo-second-order kinetic model for all prepared compounds and at the tested $\mathrm{pH}$ values were around unity as shown in Fig. 4, indicating that M(II) adsorption on chitosan and its derivatives followed the pseudo-second-order rate expression. Plotting the $\mathrm{q}_{\mathrm{t}}$ verses $\mathrm{t}^{1 / 2}$ to give curve with three periods, could be attributed to the adsorption stages of the exterior surface, interior surface, and equilibrium, respectively, as shown in Fig. 5. In case of copper ions the adsorption takes place by the exterior surface of adsorbent. When the exterior surface reached saturation, the metal ions entered into adsorbents by the pores within the particle and were adsorbed by the interior surface of the particle. When the metals ions diffused in the pores of adsorbent, the diffusion resistance increased, which caused the diffusion rate to decrease. With the decrease of the metals concentration in the solution, the diffusion rate became lower and lower, and the diffusion processes reached the final equilibrium stage. Additionally, this rate of $\mathrm{Cu}$ (II) diffusion in chitosan is faster than that of its derivatives, and this means that $\mathrm{Cu}(\mathrm{II})$ is more easily diffused and transported into pore as of chitosan than on its derivatives ${ }^{(22)}$. In case of Co(II) the maximum adsorption on the adsorbents surface occurred at $20 \mathrm{~min}$, however, with increasing of time and continuonce of steering the $\mathrm{Co}$ (II) leaves the surfaces until reached to the equilibrium at $100 \mathrm{~min}$ due to the weakly bonding with adsorbents compound. In addition, the intercepts $\mathrm{C}$ were not zero, which indicated that intraparticle diffusion may be the controlling factor in determining the kinetics of the adsorption process ${ }^{(23)}$. 

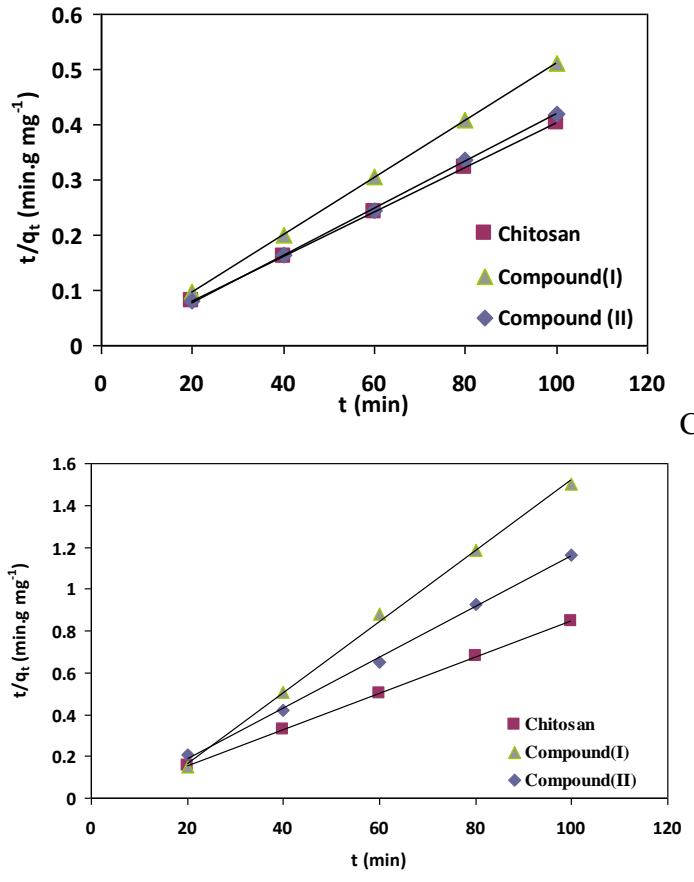

Co-chitosan alkaline medium

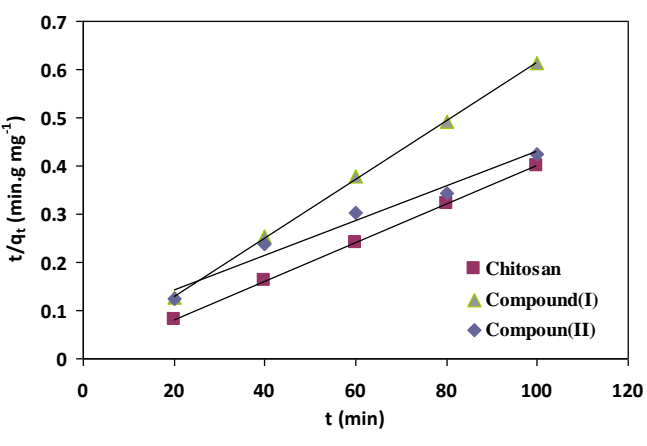

Co-chitosan neutral medium

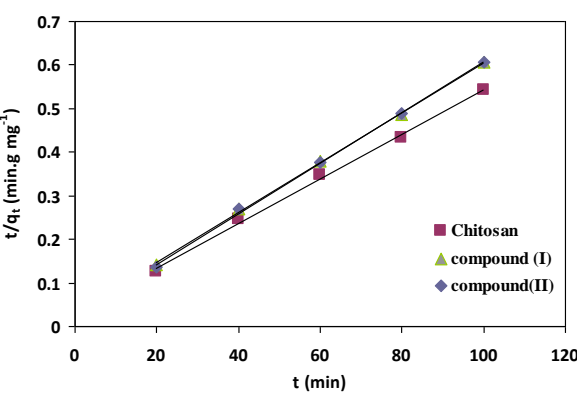

$\mathrm{Cu}$-chitosan alkaline medium

Cu-chitosan neutral medium

Fig. 4. The pseudo-second-order kinetic model of the different metals in alkaline and neutral medium.

Egypt. J. Chem. 55, No.3 (2012) 


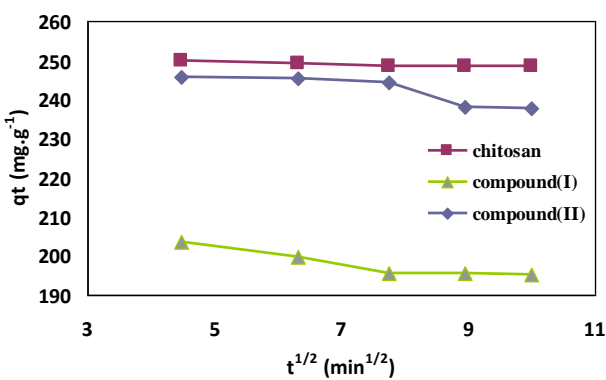

Co-chitosan alkaline medium

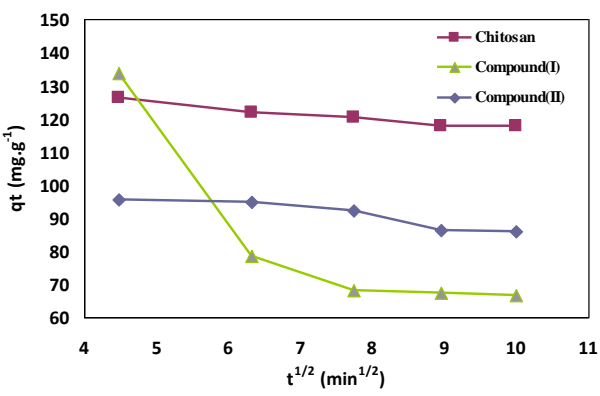

Co-chitosan neutral medium

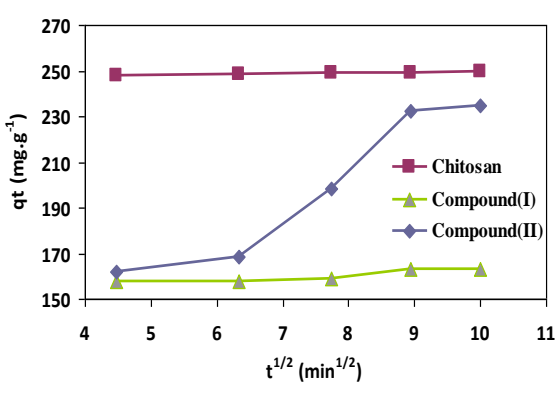

$\mathrm{Cu}$-chitosan alkaline medium

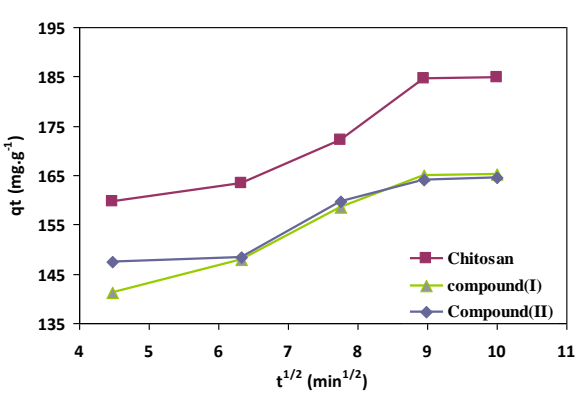

$\mathrm{Cu}$-chitosan neutral medium

Fig. 5. The intraparticle diffusion kinetic model of the different metals in alkaline and neutral medium.

Egypt. J. Chem. 55, No.3 (2012) 


\section{Adsorption isotherms}

There are several adsorption models and equations used to describe the adsorption of metal ions on the different sorbent systems. These models are: Freundlich isotherm, Toth equation, Brunauer-Emmer-Teller (BET) model, Halsey isotherm, Flory-Huggins isotherm, Dubinin-Radushkevich equation, Temkin Isotherm and the most common is the Langmuir isotherm.

Langmuir isotherm models was used to analyze the equilibrium data for M(II) adsorption on chitosan and its derivatives used as suited for characterizing monolayer adsorption process with the basic assumption that adsorption takes place at specific homogeneous sites of the adsorbent ${ }^{(24)}$. Linear plots of Langmuir isotherm models are shown in Fig. 6. Adsorption isotherm constants for Langmuir model determined in this work are given in Table 4. It can be seen that the equilibrium data for $\mathrm{M}(\mathrm{II})$ adsorption on chitosan and its derivatives fit the Langmuir model, which indicated that M(II) adsorption on the these adsorbents was a monolayer adsorption process occurring at specific homogeneous sites ${ }^{(25)}$. The Langmuir monolayer adsorption capacities $\left(\mathrm{q}_{\max }\right)$ and the Langmuir equilibrium constant $\mathrm{k}_{\mathrm{L}}$ values for chitosan were higher than the values of compounds I and II, indicating that the modification process reveres influenced M(II) adsorption equilibrium.

TABLE 4. Langmuir constants for the adsorption of $\mathrm{Co}$ (II) and $\mathrm{Cu}$ (II) onto chitosan and its derivatives.

\begin{tabular}{|c|c|c|c|c|c|c|c|c|}
\hline \multirow{2}{*}{ Comp. } & \multicolumn{2}{|c|}{ Co (pH 7) } & \multicolumn{2}{c|}{ Co (pH 9) } & \multicolumn{2}{c|}{ Cu (pH 7) } & \multicolumn{2}{c|}{$\mathbf{C u}(\mathbf{p H} 9)$} \\
\cline { 2 - 9 } & $\begin{array}{c}\mathbf{q}_{\max } \\
\left(\mathbf{m g ~ g}^{-1}\right)\end{array}$ & $\begin{array}{c}\mathbf{K}_{\mathbf{L}} \\
\left(\mathbf{L ~ g}^{-1}\right)\end{array}$ & $\begin{array}{c}\mathbf{q}_{\max } \\
\left(\mathbf{m g ~ g}^{-1}\right)\end{array}$ & $\begin{array}{c}\mathbf{K}_{\mathbf{L}} \\
\left(\mathbf{L ~ g}^{-1}\right)\end{array}$ & $\begin{array}{c}\mathbf{q}_{\max } \\
\left(\mathbf{m g ~ g}^{-1}\right)\end{array}$ & $\begin{array}{c}\mathbf{K}_{\mathbf{L}} \\
\left(\mathbf{L ~ g}^{-1}\right)\end{array}$ & $\begin{array}{c}\mathbf{q}_{\max } \\
\left(\mathbf{m g ~ g}^{-1}\right)\end{array}$ & $\begin{array}{c}\mathbf{K}_{\mathbf{L}} \\
\left(\mathbf{L ~ g ~}^{-1}\right)\end{array}$ \\
\hline Chitosan & 59.50 & 0.015 & 248.04 & 391.33 & 119.11 & 0.043 & 247.49 & 211.20 \\
\hline Comp.(I) & 36.39 & 0.012 & 159.06 & 0.098 & 94.02 & 0.027 & 102.92 & 0.031 \\
\hline Comp.(II) & 32.75 & 0.009 & 233.48 & 4.39 & 96.90 & 0.028 & 154.15 & 0.15 \\
\hline
\end{tabular}




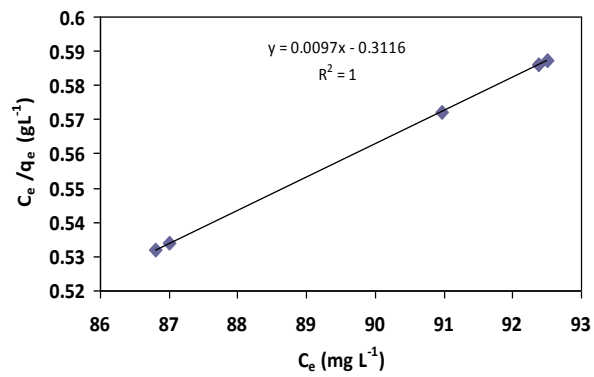

Cu-glycine chitosan derivative in alkaline medium

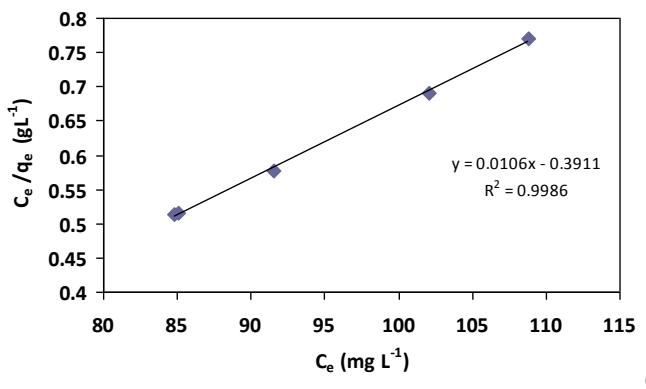

Cu-glycine chitosan derivative in neutral medium

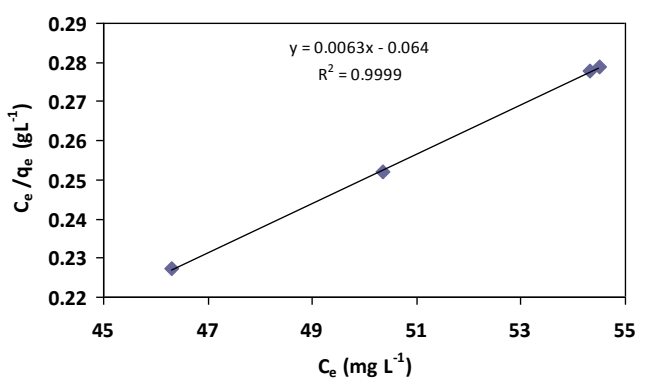

Co-glycine chitosan derivative in alkaline medium

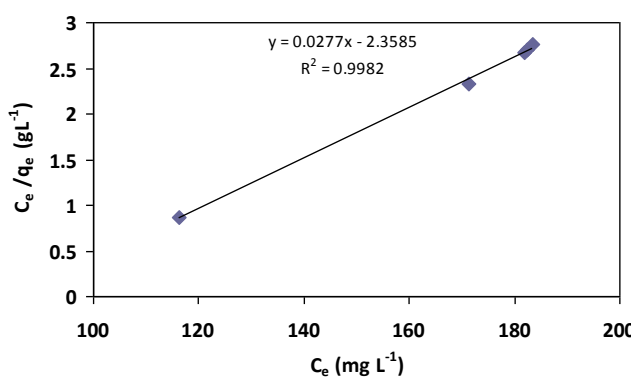

Co-glycine chitosan derivative in neutral medium

Fig. 6. Langmuir adsorption isotherm of metal adsorption on chitosan derivatives in different media.

Egypt. J. Chem. 55, No.3 (2012) 


\section{Mechanism of adsorption}

The percent removal ( $\eta \%)$ of metal ions on the active groups such as $\mathrm{OH}$ and $\mathrm{NH}_{2}$ depends on the molecular structure of the sorbent compounds, which bind to the metal ions by coordination bonds. The proposed adsorption of the transition metals by the chitosan and its derivatives were represented in Fig. 7. In our results, we found that the percent removal of the different metal ions on the surfaces of compounds (I) and (II) are lower than chitosan itself. That can be attributed to the formation of the intra-molecular hydrogen bonding between the substitution groups and unit monomer of chitosan, which leads to the decrease in the free active groups such as $\mathrm{OH}$ and $\mathrm{NH}_{2}$ on the chitosan. That causes lowering in the percent removal of metal ions. While in chitosan free which reaching by free active groups, ceasing a higher adsorption capacity than its derivatives, as shown in Scheme 1.

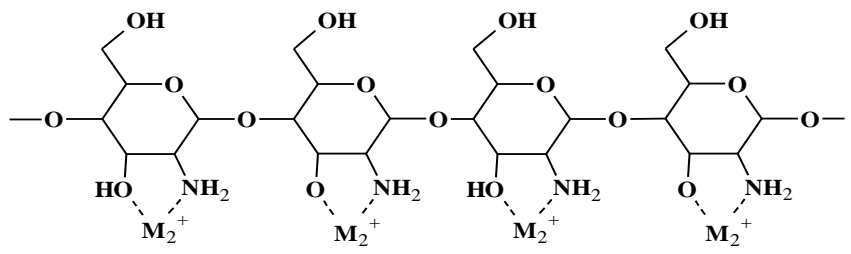

Chitosan<smiles>[Y16]C1CNNCC(NC2C(OC)OC(CO)C(OC3OC(CO)C(OC4OC(CO)C(OC5OC(CO)C(OC)C(O)C5N)C(O)C4NC(N)O)C(O)C3N)C2O)O1</smiles>

Compound(I)

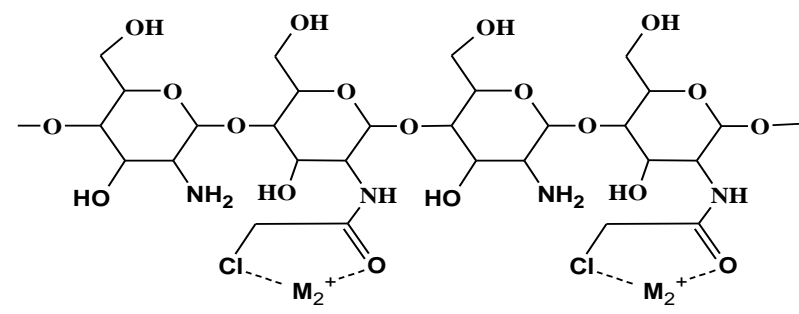

Compound(II)

Fig. 7. Adsorption of metal ions on the chitosan and its derivatives. 


\section{References}

1. Bassi, R., Prasher, S.O. and Simpson, B.K., Removal of selected metal ions from aqueous solutions using chitosan flakes. Sep. Sci. Technol. 35 , 547-560 (2000).

2. Babel, S. and Kurniawan, T.A., Low-cost adsorbents for heavy metals uptake from contaminated water: a review. J. Hazard. Mater. B97, 219-243 (2003).

3. Wu, F.C., Tseng, R.L. and Juang, R.S., Comparative adsorption of metal and dye on flake-and bead-types of chitosans prepared from fishery wastes. J. Hazard. Mater. B73, 63-75 (2000).

4. Chu, K.H., Removal of copper from aqueous solution by chitosan in prawn shell: adsorption equilibrium and kinetics. J. Hazard Mater. B90, 77-95 (2002).

5. Rengaraj, S., Yeon, K.H. and Moon, S.H., Removal of chromium from water and wastewater by ion exchange resins. J. Hazard. Mater. B87, 273-287 (2001).

6. Lee, S.T., Mi, F.L., Shen, Y.J. and Shyu, S.S., Equilibrium and kinetic studies of copper (II) ion uptake by chitosan-tripolyphosphate chelating resin. Polymer, 42, 1879-1892 (2001).

7. Mariamne, D., Margarita, H. and Roberto, C., Properties and adsorptive capacity of amino acids modified chitosans for copper ion removal. Macromol. Symp. 197, 277288 (2003).

8. Majeti, N.V. and Kumar, R., A review of chitin and chitosan applications. React. Funct. Polym. 46, 1-27 (2000).

9. Chen, X.G. and Park, H.J., Chemical characteristics of O-carboxymethyl chitosans related to the preparation conditions. Carbohydr. Polym. 53 , 355-389 (2003).

10. Choong, J. and Wolfgang, H.H., Chemical modification of chitosan and equilibrium study for mercury ion removal. Water Res. 37, 4770-4780 (2003).

11. Ho, Y.S. and McKay, G., A comparison of chemisorption kinetic models applied to pollutant removal on various sorbents. Trans. Inst. Chem. Eng. 76B, 332-340 (1998).

12. Arfaoui, S., Frini-Srasra, N. and Srasra, E., Modelling of the adsorption of the chromium ion by modified clays. Desalination , 222, 474-481 (2008).

13. Mellah, A. and Chegrouche, S., The removal of zinc from aqueous solutions by natural bentonite. Water Resour. 31 (3), 621-629 (1997).

14. Leyva Ramos, R., Bernal Jacome, L.A., Mendoza Barron, J., Fuentes Rubio, L. and Guerrero Coronado, R.M., Adsorption of zinc(II) from an aqueous solution onto activated carbon. J. Hazard. Mater. B90, 27-38 (2002).

15. Álvarez-Ayuso, E. and García-Sánchez, A., Removal of heavy metals from waste waters by natural and Na-exchanged bentonites. Clays Clay Miner. 51 (5), 475-480 (2003). 
16. Ayari, F., Srasra, E. and Trabelsi-Ayadi, M., Retention of lead from an aqueous solution by use of bentonite as adsorbent for reducing leaching from industrial effluents. Desalination, 206 , 270-278 (2007).

17. Park, M., Choi, C.L., Seo, Y.J., Yeo, S.K., Choi, J., Komarneni, S. and Lee, J.H., Reactions of $\mathrm{Cu}^{2+}$ and $\mathrm{Pb}^{2+}$ with $\mathrm{Mg} / \mathrm{Al}$ layered double hydroxide. Appl. Clay Sci. 37, 143-148 (2007)

18. Hussein, M.M., El-Hady, M.F., Sayed, W.M. and Hefni, H., Preparation of some chitosan heavy metal complexes and study of its properties. Polymer Science 54, 113124 (2012).

19. Dahiya, S., Tripathi, R.M. and Hegde, A.G., J. Hazar. Mat. 150 , 376-382 (2008).

20. Yu, J., Tong, M.S. and X.B. Li, Biochemical Engineering Journal, 33, 126-134 (2007).

21. Baral, S.S., Das, S.N. and Ath, P.R., Biochem. Eng. J. 31 , 216-221 (2006).

22. Wang, S. and Ariyanto, E., Competitive adsorption of malachite green and $\mathrm{Pb}$ ions on natural zeolite. J. Colloid Interface Sci. 314, 25-31 (2007).

23. Tang, X., Li, Z. and Chen, Y., Adsorption behavior of $\mathrm{Zn}(\mathrm{II})$ on calcinated Chinese loess. J. Hazard. Mater. 161 , 824-834 (2009).

24. Feng-Chin Wu, Ru-Ling Tseng and Ruey-Shin Juang, Journal of Environmental Management, 91 , 798-806 (2010).

25. Dural, M.U., Cavas, L., Papageorgiou, S.K. and Katsaros, F.K., Methylene blue adsorption on activated carbon prepared from Posidonia oceanica (L.) dead leaves: kinetics and equilibrium studies. Chem. Eng. J. 168, 77-85 (2011). 


\section{كفـاعة الكيتـوزان المعدل كيميائيـا فـى إدمصـاص أيونـات النـــاس والكوبالت من مياه المخلفات الصناعية}

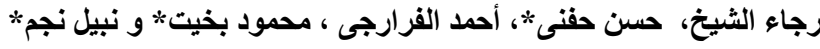

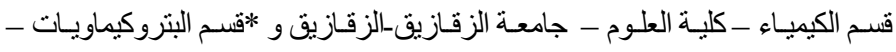

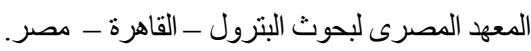

\footnotetext{
فيى هذه الدراسة تم انتاج الكينوزان و التأكد من تركيبه الكيميائى بو اسطة التحاليل

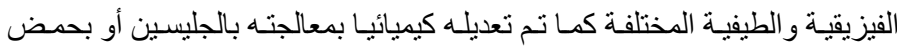

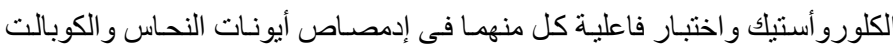

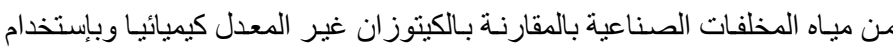

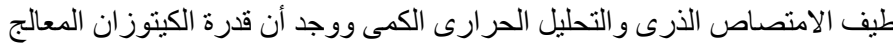

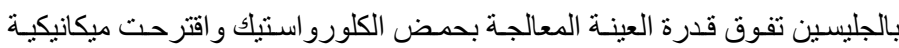

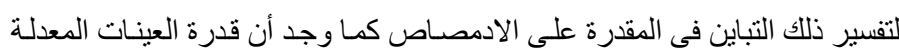

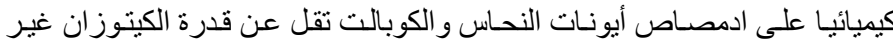
المعدل كيميائيا على ادمصاص هذه الأيونات.
} 